\title{
Centralização e descentralização: a continuidade da litoralização do crédito em Santa Catarina
}

\author{
Centralization and decentralization: the littoralisation continuity of credit in \\ Santa Catarina
}

\section{Centralisation et décentralisation: la continuité de littoralisation du crédit dans Santa Catarina}

\section{Centralización y descentralización: la continuidad de la litoralización de crédito en Santa Catarina}

Alcides Goularti Filho*

(alcides@unesc.net)

\author{
Mariane Crepaldi Zuchinali*
}

(mari_zuchi@hotmail.com)

Recebido em 30/10/2013; revisado e aprovado em 15/02/2014; aceito em 25/02/2014

\begin{abstract}
Resumo: O objetivo deste artigo é analisar como o BADESC participou da política de descentralização administrativa catarinense. Será feita uma análise comparativa entre o período 1995-2002, anterior à política de descentralização, e após a implementação da política de descentralização 2003-2010. A análise será feita com base nas unidades microrregionais das Secretarias de Desenvolvimento Regional.

Palavras-chave: Crédito. Descentralização. Desenvolvimento.

Abstract: The purpose of this article is to analyze how BADESC participated policy of administrative decentralization in Santa Catarina. Will be a comparative analysis of the period 1995-2002, before decentralization policy, and after the implementation of the decentralization policy from 2003-2010. The analysis will be based on the units of micro-regional Secretariats of Regional Development.

Key words: Credit. Decentralization. Development.

Résumé : Le fins du présent article est d'analyser comment BADESC participé politique de décentralisation administrative à Santa Catarina. Sera une analyse comparative de la période 1995-2002, avant la politique de décentralisation, et après la mise en œuvre de la politique de décentralisation 2003-2010. L'analyse sera basée sur les unités de micro régionaux de Secrétariats de Développement Régional.

Mots-clés: Crédit. Décentralisation. Développement.

Resumen: El propósito de este artículo es analizar como BADESC asistió a la descentralización administrativa política en Santa Catarina. Se realizará un análisis comparativo del período 1995-2002, antes de la política de descentralización, y después de la aplicación de la política de descentralización de 2003-2010. El análisis se basa en las unidades micro-regionales de Secretarías de Desarrollo Regional.

Palabras clave: Crédito. Descentralización. Desarrollo.
\end{abstract}

\section{Introdução: Crédito e descentralização}

Durante o período de industrialização restringida e pesada no Brasil (1930 a 1980), a limitada capacidade de acumulação financeira capitalista e a insuficiência bancária privada em sustentar os investimentos obrigaram o Estado a assumir a função de financiador do crescimento econômico (CARDOSO DE MELLO, 1988). Desse processo resulta a formação do sistema bancário público, elemento indissociável para fomentar a industrialização brasileira a partir dos anos de 1950 e estabelecer o alicerce do crescimento econômico. Dessa forma, o sistema de crédito vai além do pequeno banco, se constituindo da presença de um conjunto de bancos que tendem a induzir o capital financeiro a serviço da produção capitalista, transformando dinheiro em capital, principalmente capital industrial. Além do crédito para investimento produtivo, o sistema de crédito público estabelece o "alicerce" para o financiamento público de obras estruturantes.

O modelo de financiamento estatal brasileiro possui seus sustentáculos nos bancos públicos de desenvolvimento, sendo importante frisar a criação, em 1952, do Banco Nacional do Desenvolvimento Econômico (BNDE) e, vinculada a este, a criação, na

\footnotetext{
* Universidade do Extremo Sul Catarinense (UNESC), Criciúma, SC, Brasil.
} 
maioria dos estados brasileiros, de bancos de fomento com a finalidade de financiar o desenvolvimento regional com o crédito de longo prazo. A concepção dessa instituição propiciou a formação do sistema de crédito catarinense, pois o Estado não possuía um banco oficial para os depósitos dos repasses do Tesouro Estadual. Em Santa Catarina, em 1962, foi criado o Banco de Desenvolvimento Econômico do Estado (BDE) e, juntamente com os estados do Paraná e Rio Grande do Sul, o Banco Regional de Desenvolvimento de Extremo Sul (BRDE) (GOULARTI FILHO, 2012).

Com a extinção do BDE em 1969, como banco de fomento, Santa Catarina ficou sem nenhuma agência de fomento própria para financiar a economia industrial que, no início dos anos de 1970, estava em franca expansão. Como alternativa a esse "vazio", e com base na Lei Estadual n. 4.950, de 8 de novembro de 1973, foi criado o Banco de Desenvolvimento do Estado de Santa Catarina (Badesc), que foi efetivamente instalado somente em agosto de 1975, dentro das estratégias nacionais do II PND (Plano Nacional de Desenvolvimento). Com base na sua lei de criação, o capital inicial do Badesc seria proveniente de recursos orçamentários, da participação do Estado nos recursos próprios do BRDE e créditos especiais. Ao longo da sua existência, procurou diversificar os setores econômicos e as regiões beneficiadas. O banco transformou-se no principal agente de fomento da economia catarinense e em um forte aliado dos governadores, para cumprir as metas estabelecidas em seus planos de governos. Repassando recursos do BNDES, ou operando com recursos próprios, o Badesc consolidou-se como uma alavanca para o crescimento industrial e agroindustrial de Santa Catarina (GOULARTI FILHO, 2012).

Em 1998, de acordo com diretrizes do Banco Central do Brasil, passou a chamarse Agência de Fomento do Estado de Santa Catarina, atuando também em operações de microcrédito.

No contexto dos objetivos estatais de desenvolvimento econômico, o papel atribuído ao Badesc foi promover o desenvolvimento econômico e social catarinense, mediante a prática da aplicação de recursos financeiros, no âmbito de sua competência, atuando com relativa autonomia no fomento das atividades produtivas catarinenses, financiamento de projetos públicos e incentivos públicos, com operações de crédito de recursos próprios ou fazendo repasses do BNDES e de demais agências financeiras nacionais e internacionais.

Visando à descentralização da administração pública estadual e à desconcentração do poder decisório, até então centralizados e hierarquizados em Florianópolis, o governo do Estado de Santa Catarina realizou a implantação de um novo modelo de gestão no início do mandato do governador Luiz Henrique da Silveira, em 2003. O intuito dessa mudança foi ampliar a atuação governamental para todo o território catarinense; desse modo, a descentralização e desconcentração possibilitam a transferência do poder decisório, antes centrado na capital do Estado para outras regiões.

Para efetivar essa proposta, o governo incorporou e aprovou a Lei Complementar Estadual n. 243/2003, cujo art. $9^{\circ}$ estabelece que "a execução das atividades da administração estadual será descentralizada e desconcentrada e se dará preponderantemente pelas Secretarias de Estado do Desenvolvimento Regional e por outros órgãos de atuação regional" (SANTA CATARINA, 2003). O motivo primordial da adoção dessa política de governo era ampliar a participação popular no processo decisório, ciente das especificidades sociais, econômicas e culturais de cada região.

A referida Lei Complementar Estadual n. $243 / 2003$, art. 26 , dispõe sobre a criação de 29 Secretarias de Estado do Desenvolvimento Regional para atuar como órgão executivo do governo em cada região administrativa de competência (SANTA CATARINA, 2003). A Lei Complementar Estadual n. 284/2005, art. 74, estabeleceu a criação de mais uma SDR (SANTA CATARINA, 2005). E a Lei Complementar Estadual n. 381/2007 instituiu mais seis secretarias, chegando a um total de 36 SDRs (SANTA CATARINA, 2007). As SDRs são listadas a seguir na Tabela 1. 
Tabela 1 - Secretarias de Estado de Desenvolvimento Regional

\begin{tabular}{l|l}
\hline \multicolumn{2}{c}{ Secretarias de Estado } \\
de Desenvolvimento Regional
\end{tabular}

Fonte: SANTA CATARINA, 2007

O discurso governamental infere sobre os motivos e a motivação de adotar essa política, e Batista (2010, p. 12) corrobora para explicitar o discurso de Luiz Henrique descrevendo que:

[...] a implantação da descentralização como modelo de governo se tornou uma forma de intervenção nas relações entre sociedades e instituições, que aproximava cada vez mais cidades e regiões. Acrescentando que as SDR (Secretarias de Desenvolvimento Regional) não seriam apenas uma manobra "logística do governo do Estado", mas que as comunidades microrregionais têm a possibilidade de elencar as suas necessidades para o melhor desenvolvimento de seus municípios. [...] a descentralização do Estado foi inspirada na ideia colocada na prática quando prefeito da cidade Joinville, que tinha como objetivo construir uma cidade "policêntrica". Mas o governador teve como principal exemplo os modelos de gestão pública aplicados em países europeus, como na Alemanha, onde a gestão acontece através de subdistritos.

Por conseguinte, para auxiliar as SDRs no planejamento regional, apoiar projetos e planos de desenvolvimento econômico e social, entre outras funções acessórias, a Lei Complementar Estadual n. 243/2003, art. 57, criou os Conselhos de Desenvolvimento Regional (CDRs).

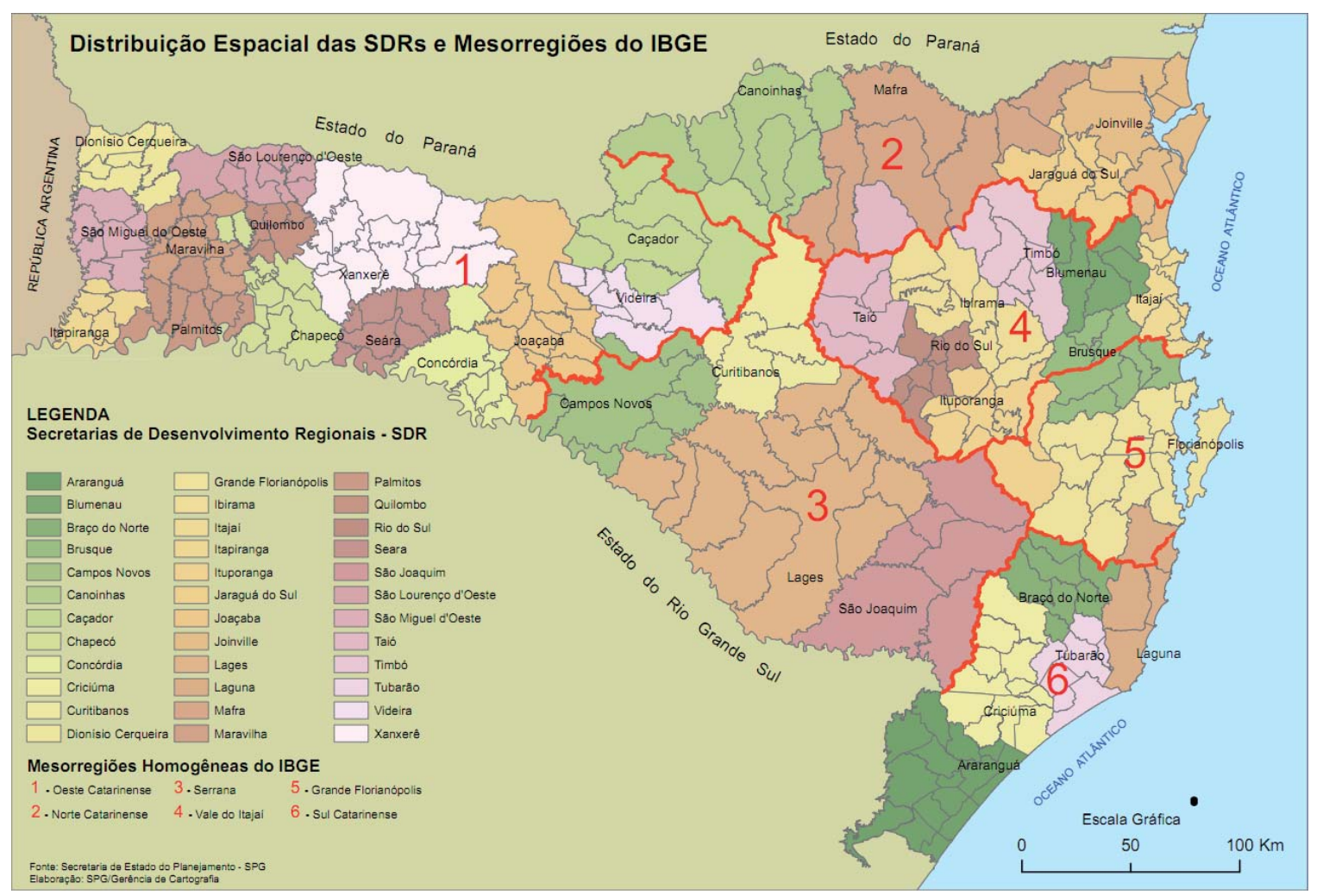

Figura 1 - Distribuição Espacial das SDRs e Mesorregiões.

Fonte: Secretaria de Estado do Planejamento - SPG 


\section{Descentralização e federalismo brasileiro}

A difusão vigorosa do processo de descentralização internacionalmente nos remete aos seus principais determinantes, vale ressaltar a desestruturação do nacional-desenvolvimentismo em países subdesenvolvidos; a crise do Welfare-State nos países desenvolvidos; a emergência da globalização ou a dissipação do capital mundial acompanhado do enfraquecimento do poder regulatório dos Estados nacionais; bem como a retomada do ideário liberalista aliada à redução do papel estatal na economia (AFFONSO, 2000).

$\mathrm{Na}$ grande maioria dos países da América Latina, segundo Affonso (2000), a descentralização ocorreu devido aos processos de redemocratização, aos problemas de governabilidade e à crise fiscal. Na maioria dos casos, a descentralização fiscal começou como forma de distribuir atribuições aos governos subnacionais. Em alguns países, a descentralização fiscal esteve associada à necessidade de repassar encargos para as unidades subnacionais a fim de amenizar crises de governabilidade. Em outros países, o esforço da descentralização fiscal foi em prol da redemocratização na qual a sociedade reivindica maior participação nas receitas fiscais. Este último caracteriza o caso brasileiro.

Afirmar que a descentralização no Brasil possui tendência à federalização é relatar a recente associação que se faz entre esses dois termos, pois a descentralização estaria atrelada à ideia de aumentar a "[...] eficiência do setor público como prestador de serviços à população" devido a esse "[...] processo de transferência de poder político-econômico para unidades subnacionais de governo" (AFFONSO, 2000, p. 127), um dos escopos do federalismo. Mas é importante frisar que o acentuado grau de descentralização brasileira está relacionado tanto em termos de configuração política e institucional quanto de estrutura tributária e fiscal.

A descentralização e o federalismo possuem suas peculiaridades conceituais, eles constituem juntos "[...] uma resposta do Estado à necessidade de atender à multiplicidade de demandas territorialmente diferenciadas, ou seja, de enfrentar o desafio de articular o "geral" com as "particularidades" na gestão pública" (AFFONSO, 2000, p. 130). Todavia a
Federação caracteriza-se pela propagação de poderes em vários centros, ou unidades, na qual a autoridade é concedida por sufrágio universal e não simplesmente por concessão ou permissão, como geralmente ocorre na descentralização. Analisar a relação entre esses dois termos historicamente é de extrema relevância, pois, quando se parte de uma situação de centralismo, o federalismo se identifica com a descentralização (exemplo brasileiro), caso contrário, ele pode significar uma centralização do poder territorial (federação americana).

É relevante ressaltar que a análise contemporânea do federalismo brasileiro esbarra em problemas conceituais relacionados à centralização-descentralização. Assim, conforme Almeida (1995, p. 91),

[...] o termo "descentralização" está longe de ter um significado preciso. Ele tem sido utilizado indistintamente para indicar graus e modalidades diversas de redução do escopo do governo federal em decorrência: a) do deslocamento da capacidade de decidir e implementar políticas para instâncias subnacionais; b) da transferência para outras esferas de governo da implementação e administração de políticas definidas no plano federal; ou c) da passagem de atribuições da área governamental para o setor privado.

Almeida (1995) discerne ainda que o federalismo não possa ser confundido com a descentralização e também que o termo "não-centralização" não possuiu o mesmo significado que descentralização.

Para Guimarães de Castro (1991), a instauração da descentralização no Brasil ocorreu após o esgotamento dos regimes burocrático-autoritários dos anos de 1960, decorrentes do exacerbado autoritarismo militar do Estado centralizado, visto que o "modelo desenvolvimentista" não sustentava mais o crescimento igualitário da renda (GUIMARÃES DE CASTRO, 1991). O gasto público passou a ser sinônimo de inflação e péssimo desempenho econômico, assim as propostas de descentralização foram amplamente defendidas e consagradas na Constituição Federal de 1988 (GUIMARÃES DE CASTRO, 1991).

Entretanto Kugelmas e Sola (1999) alertam para os equívocos existentes quando se considera metaforicamente que o federalismo acompanharia os movimentos 
descentralizadores e centralizadores, estes estariam atrelados a períodos autoritários ou aos avanços democráticos, ou seja, o federalismo também acompanharia estes períodos alternantes. Contudo, Kugelmas e Sola (1999) ressaltam que inexiste simetria nessas oscilações, assim o centralismo não necessariamente desestrutura a Federação e, da mesma forma, que a descentralização federativa não significa democratização.

A grande característica da redemocratização brasileira reside no fato de ela ter ocorrido primeiramente nos governos subnacionais (anos 80$)$, com a eleição de prefeitos e governadores, para somente nos anos 90 ela abordar a União, com a eleição direta para a Presidência da República. Assim, a descentralização, conforme Affonso (2000), não promoveu a compensação esperada de alguns estados e municípios pela distribuição de encargos e receitas.

Affonso (2000) destaca que uma das características da federalização brasileira é a marcante desigualdade socioeconômica entre as unidades federadas, sendo que tal heterogeneidade constitui um entrave ao desenvolvimento, pois dificulta a coordenação federativa em um grau superior de descentralização. A complexidade do aparato estatal, outra característica, também atua de forma diferenciada regional e intrarregionalmente.

É perceptível a grande dificuldade do governo central em solucionar problemas que o Estado Nacional-desenvolvimentista tentou resolver e que perpetuam mesmo após a incorporação da descentralização-federalização. Estes últimos não incluíram conteúdos sociais na pauta da trajetória da estrutura brasileira, e assim outras formas de desigualdade entre as regiões vêm se desenvolvendo, consiste nesta e na permanência do pensamento individualista da elite social mais privilegiada a dificuldade de adotar políticas públicas gerais (AFFONSO, 2000). Organizar descentralizadamente uma federação assentada em disparidades regionais e com diversas lacunas na divisão de competências entre as esferas de governo é uma tarefa árdua. Ostentam alguns autores que a descentralização é o instrumento capaz de implantar um projeto de desenvolvimento geral neste território imenso, principalmente proporcionando a redistribuição espacial de recursos de forma a não afetar as classes sociais mais desfavorecidas. Outros autores diriam que a descentralização constituiria o abandono de qualquer anseio de desenvolvimento entre regiões e no interior destas, deixando ao mercado a incumbência da alocação de recursos (AFFONSO, 1995).

\section{Centralização, descentralização e descon- centração administrativa}

A centralização administrativa está circunscrita na forma da administração direta, e esta configura o "[...] conjunto dos órgãos integrados na estrutura da chefia do Executivo e na estrutura dos órgãos auxiliares da chefia do Executivo" (MEDAUAR, 2009, p. 63). Assim, de acordo com este autor, os vínculos hierárquicos e de subordinação entre os órgãos que compõem a administração direta são uma das características principais na determinação das funções exercidas. Para cumprir tais atribuições e tarefas, efetua-se a distribuição entre os órgãos da administração em uma mesma entidade ou pessoa jurídica, a denominada desconcentração (MEDAUAR, 2009).

Corroborando com isso, Di Pietro (2006) afirma que a desconcentração possibilita a distribuição de competências dentro da mesma pessoa jurídica, organizada hierarquicamente e partindo do chefe Executivo para seus demais auxiliares. Nesse sentido, a ostentação está em "descongestionar, desconcentrar, tirar do centro um volume grande de atribuições, para permitir seu mais adequado e racional desempenho" (DI PIETRO, 2006, p. 403).

A descentralização administrativa é amparada pela administração indireta, e, portanto, inexistem vínculos de hierarquia, e a distribuição de competências necessita de ao menos duas pessoas, física ou jurídica (DI PIETRO, 2006). Com base neste mesmo autor, a descentralização consiste na transferência de atribuições do ente central ao descentralizado, entretanto, apesar de as entidades possuírem capacidade de conduzir seus negócios, elas não têm autonomia para gestar suas próprias leis, ou seja, estão subordinadas ao poder central.

Medauar (2009, p. 61) destaca que os entes descentralizados englobam " [...] autarquias, empresas públicas, sociedades de economia mista e fundações públicas [...]". Para 
descentralizar, o poder central deve respeitar as normas estabelecidas de controle do ente descentralizado, a denominada tutela ou controle administrativo, que difere amplamente do caráter hierárquico da administração direta, pois a tutela controla entidades jurídicas com poder decisório próprio (MEDAUAR, 2009).

Na concepção de Meirelles (2004), o Poder Público pode descentralizar determinado serviço público, tanto pela transferência de titularidade como permitindo apenas sua execução, por meio de outorga ou delegação. A outorga ocorre "[...] quando o Estado cria uma entidade e a ela transfere, por lei, determinado serviço público ou de utilidade pública" (MEIRELLES, 2004, p. 331). Na delegação a transferência do serviço é exclusivamente para execução mediante contrato (concessão) ou ato unilateral (permissão ou autorização). Portanto, aquele possui um caráter definitivo, pois é transferido e retirado por lei, e este mais temporário já que tem prazo final de contrato (MEIRELLES, 2004). Em ambos os casos, o serviço descentralizado continua sendo público, controlado e regulado pelo poder público.

\section{Desembolso do Badesc para as SDRs}

Visando acelerar o desenvolvimento regional catarinense e articular os níveis de planejamento com maior envolvimento social, o Estado adotou a proposta de descentralização administrativa por intermédio da instituição das SDRs. Sucintamente, o processo é fruto do pensamento liberal que defende a ideia de desenvolvimento local. Apesar de alguns autores defenderem tal modelo de gestão, ainda é grande a discussão acerca de seus reflexos para a economia nacional e regional. Portanto as análises a seguir contribuirão para nortear o desígnio do trabalho, ou seja, obter conclusões sobre a descentralização do crédito público de acordo com a atual formação das SDRs.

Para podermos comparar se o Badesc também descentralizou o crédito entre 2003 e 2010, período que abrange os dois mandatos de Luiz Henrique da Silveira, construímos uma série histórica de 1995 a 2010, dividida em dois períodos 1995-2002 (sem descentralização) e 2003-2010 (com descentralização). Tomando como referência a divisão das SDRs, retroagimos com a mesma metodologia de classificação também para os anos entre 19952002, isto é, hipoteticamente criamos as SDRs em 1995, somente assim poderíamos fazer a comparação entre os dois períodos. Todos os valores em reais foram deflacionados tendo como ano-base 2010.

Utilizando essa metodologia retroativa, a Tabela 2 revela que 21 SDRs apresentaram aumento, de um período para outro, nos valores contratados no Badesc. No total geral houve uma queda no quantitativo de recursos liberados pela instituição, no equivalente a R\$ 43.899.115,90. 
Tabela 2 - Desembolso do Badesc por SDR (em R\$)

\begin{tabular}{|c|c|c|c|}
\hline SDRs & $\begin{array}{c}\text { Valores Contratados (R\$) } \\
1995 \text { a } 2002\end{array}$ & $\begin{array}{c}\text { Valores Contratados (R\$) } \\
2003 \text { a } 2010\end{array}$ & Diferença (R\$) \\
\hline São Miguel do Oeste & $4.169 .290,1$ & $5.376 .475,6$ & $1.207 .185,5$ \\
\hline Maravilha & $5.031 .592,6$ & $16.126 .969,0$ & $11.095 .376,3$ \\
\hline São Lourenço do Oeste & $18.281 .514,6$ & $14.231 .119,4$ & $-4.050 .395,2$ \\
\hline Chapecó & $28.699 .285,2$ & $50.104 .084,1$ & $21.404 .798,9$ \\
\hline Xanxerê & $13.137 .828,4$ & $34.598 .132,5$ & $21.460 .304,1$ \\
\hline Concórdia & $18.307 .770,4$ & $6.269 .754,8$ & $-12.038 .015,7$ \\
\hline Joaçaba & $60.371 .973,0$ & $12.932 .061,7$ & $-47.439 .911,3$ \\
\hline Videira & $43.937 .378,2$ & $13.188 .912,9$ & $-30.748 .465,3$ \\
\hline Caçador & $33.711 .084,4$ & $14.849 .563,3$ & $-18.861 .521,1$ \\
\hline Palmitos & $4.976 .056,6$ & $6.046 .866,3$ & $1.070 .809,7$ \\
\hline Dionísio Cerqueira & $1.905 .703,4$ & $3.384 .957,8$ & $1.479 .254,5$ \\
\hline Itapiranga & $796.895,1$ & $6.492 .314,3$ & $5.695 .419,1$ \\
\hline Seara & $7.414 .688,8$ & $7.573 .139,3$ & $158.450,5$ \\
\hline Quilombo & $447.076,0$ & $2.900 .349,0$ & $2.453 .273,0$ \\
\hline Canoinhas & 21.607.361,4 & $31.893 .741,9$ & $10.286 .380,5$ \\
\hline Mafra & $34.174 .649,9$ & $31.060 .551,6$ & $-3.114 .098,3$ \\
\hline Joinville & $96.361 .886,2$ & $87.411 .949,1$ & $-8.949 .937,1$ \\
\hline Jaraguá do Sul & $37.495 .708,7$ & $78.667 .293,5$ & $41.171 .584,7$ \\
\hline Campos Novos & $5.047 .659,2$ & $9.167 .198,0$ & $4.119 .538,8$ \\
\hline Curitibanos & $5.129 .095,2$ & $3.800 .858,8$ & $-1.328 .236,3$ \\
\hline Lages & $33.489 .823,4$ & $24.193 .792,8$ & $-9.296 .030,6$ \\
\hline São Joaquim & $8.846 .625,8$ & $3.647 .900,0$ & $-5.198 .725,8$ \\
\hline Itajaí & $51.954 .420,2$ & $67.951 .764,0$ & $15.997 .343,8$ \\
\hline Taió & $7.870 .370,3$ & $4.404 .129,7$ & $-3.466 .240,6$ \\
\hline Timbó & $14.970 .398,6$ & $20.188 .834,3$ & $5.218 .435,6$ \\
\hline Blumenau & $77.794 .776,3$ & $68.697 .868,1$ & $-9.096 .908,2$ \\
\hline Ibirama & $3.303 .455,7$ & $4.132 .398,6$ & $828.942,9$ \\
\hline Rio do Sul & $14.572 .481,0$ & $48.793 .778,1$ & $34.221 .297,1$ \\
\hline Ituporanga & $4.424 .705,2$ & $4.541 .600,6$ & $116.895,4$ \\
\hline Brusque & $99.263 .776,3$ & $43.360 .355,9$ & $-55.903 .420,5$ \\
\hline Grande Florianópolis & $101.184 .258,7$ & $130.957 .937,9$ & $29.773 .679,2$ \\
\hline Araranguá & $12.432 .508,3$ & $17.070 .964,1$ & $4.638 .455,8$ \\
\hline Criciúma & $68.734 .807,5$ & $36.746 .001,5$ & $-31.988 .806,0$ \\
\hline Laguna & $5.566 .954,9$ & $9.744 .299,3$ & $4.177 .344,4$ \\
\hline Tubarão & $34.631 .210,0$ & $12.319 .831,2$ & $-22.311 .378,7$ \\
\hline Braço do Norte & $15.347 .120,8$ & $18.665 .325,8$ & $3.318 .205,0$ \\
\hline Total & $995,392,190,3$ & 951.493 .074 .5 & -43.8991159 \\
\hline
\end{tabular}

Fonte: BADESC - Agência de Fomento do Estado de Santa Catarina. 
Tabela 3 - Desembolso do Badesc por SDR (em \%)

\begin{tabular}{|c|c|c|}
\hline SDRs & $\begin{array}{c}\text { Valores Contratados (\%) } \\
1995 \text { a } 2002\end{array}$ & $\begin{array}{c}\text { Valores Contratados (\%) } \\
2003 \text { a } 2010\end{array}$ \\
\hline São Miguel do Oeste & 0,4 & 0,6 \\
\hline Maravilha & 0,5 & 1,7 \\
\hline São Lourenço do Oeste & 1,8 & 1,5 \\
\hline Chapecó & 2,9 & 5,3 \\
\hline Xanxerê & 1,3 & 3,6 \\
\hline Concórdia & 1,8 & 0,7 \\
\hline Joaçaba & 6,1 & 1,4 \\
\hline Videira & 4,4 & 1,4 \\
\hline Caçador & 3,4 & 1,6 \\
\hline Palmitos & 0,5 & 0,6 \\
\hline Dionísio Cerqueira & 0,2 & 0,4 \\
\hline Itapiranga & 0,1 & 0,7 \\
\hline Seara & 0,7 & 0,8 \\
\hline Quilombo & 0,0 & 0,3 \\
\hline Canoinhas & 2,2 & 3,4 \\
\hline Mafra & 3,4 & 3,3 \\
\hline Joinville & 9,7 & 9,2 \\
\hline Jaraguá do Sul & 3,8 & 8,3 \\
\hline Campos Novos & 0,5 & 1,0 \\
\hline Curitibanos & 0,5 & 0,4 \\
\hline Lages & 3,4 & 2,5 \\
\hline São Joaquim & 0,9 & 0,4 \\
\hline Itajaí & 5,2 & 7,1 \\
\hline Taió & 0,8 & 0,5 \\
\hline Timbó & 1,5 & 2,1 \\
\hline Blumenau & 7,8 & 7,2 \\
\hline Ibirama & 0,3 & 0,4 \\
\hline Rio do Sul & 1,5 & 5,1 \\
\hline Ituporanga & 0,4 & 0,5 \\
\hline Brusque & 10,0 & 4,6 \\
\hline Grande Florianópolis & 10,2 & 13,8 \\
\hline Araranguá & 1,2 & 1,8 \\
\hline Criciúma & 6,9 & 3,9 \\
\hline Laguna & 0,6 & 1,0 \\
\hline Tubarão & 3,5 & 1,3 \\
\hline Braço do Norte & 1,5 & 2,0 \\
\hline Total & 100,0 & 100,0 \\
\hline
\end{tabular}

Fonte: BADESC - Agência de Fomento do Estado de Santa Catarina.

De acordo ainda com a Tabela 2, as SDRs que tiveram relevante aumento na contratação de crédito público são: Maravilha, Chapecó, Xanxerê, Canoinhas, Jaraguá do Sul, Itajaí, Rio do Sul e Grande Florianópolis. Positivamente, a maior diferença em contratação foi de R\$41.171.584,70, da SDR de Jaraguá do Sul. Entre as 15 SDRs que apresentaram redução na contratação de recursos com relação ao período antecedente estão as de Joaçaba, Videira, Brusque, Criciúma e Tubarão. A SDR de Brusque apresentou a maior queda nas contratações (R \$ 55.903.420,50).

Por conseguinte, conforme a Tabela 3, as SDRs que já possuíam ampla participação e que a elevaram no segundo período foram as SDRs da Grande Florianópolis $(13,8 \%)$, Jaraguá do Sul $(8,3 \%)$ e Itajaí $(7,1 \%)$, todas localizadas próximo ao litoral (Figura 1). Algumas continuam tendo apreciável presença no total, mas perderam espaço no período de 2003 a 2010, são elas: Blumenau (7,2\%), Brusque 
$(4,6 \%)$, Criciúma $(3,9 \%)$ e Joinville $(9,2 \%)$.

A Tabela 4 evidencia que três mesorregiões (Norte, Vale do Itajaí e Grande
Florianópolis) aumentaram os valores contratados no Badesc entre períodos, enquanto as três outras (Oeste, Serrana e Sul) reduziram.

Tabela 4 - Desembolso do Badesc por mesorregião (em R\$)

\begin{tabular}{cccc}
\hline Mesorregiões & Valores Contratados (R\$) & Valores Contratados (R\$) & Diferença \\
\hline Oeste Catarinense & $240.737 .797,9$ & $\mathbf{2 0 0 3}$ a 2010 & $-46.417 .988,1$ \\
Norte Catarinense & $189.241 .772,3$ & $194.319 .809,9$ & $36.937 .140,2$ \\
Serrana & $52.498 .513,6$ & $226.178 .912,5$ & $-12.323 .874,0$ \\
Vale do Itajaí & $229.510 .714,2$ & $40.174 .639,6$ & $16.888 .759,4$ \\
Grande Florianópolis & $147.899 .474,8$ & $246.399 .473,7$ & $3.789 .342,1$ \\
Sul Catarinense & $135.503 .917,4$ & $151.688 .816,9$ & $-42.772 .495,5$ \\
\hline Total & $995.392 .190,3$ & $92.731 .421,9$ & $-43.899 .115,9$ \\
\hline
\end{tabular}

Fonte: BADESC - Agência de Fomento do Estado de Santa Catarina.

Assim, dentre as três mesorregiões que apresentaram queda absoluta na contratação de recursos com relação ao período anterior, as mais significativas foram as do Oeste e Sul Catarinense. A mesorregião com maior acréscimo na contratação foi o Norte, ostentando cerca de $\mathrm{R} \$ 36.937 .140,20$ a mais de recursos.

A participação no total dos recursos do Badesc (Tabela 5) para o primeiro período é expressiva para as mesorregiões do Oeste $(24,2 \%)$, Norte (19\%) e Vale do Itajaí $(23,1 \%)$, porém a participação do Oeste Catarinense decresce no período de 2003 a 2010, chegando a $20,4 \%$. As demais aumentam sua participação. O Norte passa a ter $23,8 \%$, e o Vale do Itajaí, 25,9\%.

É importante frisar que as mesorregiões do sul catarinense e serrana, que apresentavam pouca participação no primeiro período, decaíram ainda mais sua participação de $13,6 \%$ e $5,3 \%$ para $9,7 \%$ e $4,2 \%$, respectivamente.

Tabela 5 - Desembolso do Badesc por mesorregião (em \%)

\begin{tabular}{ccc}
\hline Mesorregiões & $\begin{array}{c}\text { Valores Contratados (\%) } \\
\text { 1995 a 2002 }\end{array}$ & $\begin{array}{c}\text { Valores Contratados (\%) } \\
\text { 2003 a 2010 }\end{array}$ \\
\hline Oeste Catarinense & 24,2 & 20,4 \\
Norte Catarinense & 19,0 & 23,8 \\
Serrana & 5,3 & 4,2 \\
Vale do Itajaí & 23,1 & 25,9 \\
Grande Florianópolis & 14,9 & 15,9 \\
Sul Catarinense & 13,6 & 9,7 \\
\hline Total & 100,0 & 100,0 \\
\hline
\end{tabular}

Fonte: BADESC - Agência de Fomento do Estado de Santa Catarina.

Embora seja evidente que um grande número de SDRs (21) tenha aumentado os recursos adquiridos no Badesc, de acordo com a Tabela 3, apenas 12 (Chapecó, Xanxerê, Canoinhas, Mafra, Joinville, Jaraguá do Sul, Itajaí, Blumenau, Rio do Sul, Brusque, Grande Florianópolis e Criciúma) obtiveram participação maior de 3\% do total no segundo período. Algumas (Jaraguá do Sul, Itajaí e Grande Florianópolis) já estavam nesse patamar anteriormente, conseguindo aumentar ainda mais essa participação. Outras (Chapecó, Xanxerê, Canoinhas e Rio do Sul), entretanto, só conseguiram esse percentual de participação no segundo período, o que demonstra que, mesmo com o aumento na contratação de crédito, algumas SDRs não conseguem se posicionar mais positivamente no total dos recursos desembolsados. Ou seja, apenas o aumento na contratação de crédito 
pouco contribui para expressar a realidade da distribuição dos recursos no Estado, sendo necessário analisar-lhe a concentração por intermédio do percentual de participação.

A Figura 1 e a Tabela 6 permitem analisar em um novo enfoque, relevante também para o esboço do estudo, possibilitando identificar em quais mesorregiões localizam-se as SDRs com maior participação e atribuir esclarecimentos sobre o desempenho daquelas.
Assim, a Tabela 6, na verdade apenas apresenta novamente os dados da participação das SDRs expostos na Tabela 3, agrupando-as de acordo com as mesorregiões. É necessário realizar um adendo, lembrando que, para fins de simplificação, é desconsiderada a ocorrência de alguns municípios pertencentes a determinadas SDRs ultrapassarem a divisa das mesorregiões.

Tabela 6 - Desembolso do Badesc por SDRs de acordo com suas respectivas mesorregiões (em \%)

\begin{tabular}{|c|c|c|c|}
\hline Mesorregiões & SDRs & $\begin{array}{c}\text { Valores Contratados (\%) } \\
1995 \text { a } 2002 \\
\end{array}$ & $\begin{array}{c}\text { Valores Contratados (\%) } \\
003 \text { a } 2010\end{array}$ \\
\hline \multirow{14}{*}{ Oeste Catarinense } & São Miguel do Oeste & 0,4 & 0,6 \\
\hline & Maravilha & 0,5 & 1,7 \\
\hline & São Lourenço do Oeste & 1,8 & 1,5 \\
\hline & Chapecó & 2,9 & 5,3 \\
\hline & Xanxerê & 1,3 & 3,6 \\
\hline & Concórdia & 1,8 & 0,7 \\
\hline & Joaçaba & 6,1 & 1,4 \\
\hline & Videira & 4,4 & 1,4 \\
\hline & Caçador & 3,4 & 1,6 \\
\hline & Palmitos & 0,5 & 0,6 \\
\hline & Dionísio Cerqueira & 0,2 & 0,4 \\
\hline & Itapiranga & 0,1 & 0,7 \\
\hline & Seara & 0,7 & 0,8 \\
\hline & Quilombo & 0,0 & 0,3 \\
\hline \multirow{4}{*}{ Norte Catarinense } & Canoinhas & 2,2 & 3,4 \\
\hline & Mafra & 3,4 & 3,3 \\
\hline & Joinville & 9,7 & 9,2 \\
\hline & Jaraguá do Sul & 3,8 & 8,3 \\
\hline \multirow{4}{*}{ Serrana } & Campos Novos & 0,5 & 1,0 \\
\hline & Curitibanos & 0,5 & 0,4 \\
\hline & Lages & 3,4 & 2,5 \\
\hline & São Joaquim & 0,9 & 0,4 \\
\hline \multirow{8}{*}{ Vale do Itajaí } & Itajaí & 5,2 & 7,1 \\
\hline & Taió & 0,8 & 0,5 \\
\hline & Timbó & 1,5 & 2,1 \\
\hline & Blumenau & 7,8 & 7,2 \\
\hline & Ibirama & 0,3 & 0,4 \\
\hline & Rio do Sul & 1,5 & 5,1 \\
\hline & Ituporanga & 0,4 & 0,5 \\
\hline & Brusque & 10,0 & 4,6 \\
\hline $\begin{array}{c}\text { Grande Florianópo- } \\
\text { lis }\end{array}$ & Grande Florianópolis & 10,2 & 13,8 \\
\hline \multirow{5}{*}{ Sul Catarinense } & Araranguá & 1,2 & 1,8 \\
\hline & Criciúma & 6,9 & 3,9 \\
\hline & Laguna & 0,6 & 1,0 \\
\hline & Tubarão & 3,5 & 1,3 \\
\hline & Braço do Norte & 1,5 & 2,0 \\
\hline Total & & 100,0 & 100,0 \\
\hline
\end{tabular}

Fonte: BADESC - Agência de Fomento do Estado de Santa Catarina. 
A mesorregião Oeste Catarinense, de acordo com a Tabela 5, apresentou grande participação em ambos os períodos, embora tenha perdido espaço. Uma característica pertinente que pode explicar essa grande participação é o fato de possuir muitas SDRs em seu domínio (14). Apesar disso, a queda pode ser atribuída à acentuada perda de participação das SDRs de Joaçaba, Videira, Caçador, Concórdia e São Lourenço do Oeste, que não foi compensada pelo aumento das demais SDRs desta mesorregião (Tabela 6).

De acordo com a Tabela 6, todas as SDRs pertencentes à mesorregião do Norte tiveram considerável participação em ambos os períodos, principalmente Joinville $(9,7 \%$ 9,2\%) e Jaraguá do Sul (3,8\% - 8,3\%). O Vale do Itajaí também faz jus a sua posição em consequência das SDRs de Itajaí $(5,2 \%-7,1 \%)$, Blumenau $(7,8 \%-7,2 \%)$, Rio do Sul $(1,5 \%$ $5,1 \%)$ e Brusque $(10 \%-4,6 \%)$ estarem bem situadas nos termos analisados. A Grande Florianópolis, nos dois períodos, foi a SDR que apresentou máxima participação $(10,2 \%$ $-13,8 \%)$, e de forma crescente, corroborando com sua respectiva mesorregião $(14,9 \%$ $15,9 \%)$.

Ademais, as SDRs da mesorregião Serrana e do Sul não apresentaram melhora expressiva na participação entre um período e outro, algumas até mesmo perderam espaço, o que refletiu na queda na participação dessas duas mesorregiões.

\section{Reflexões finais}

A abordagem utilizada para analisar os dados evidencia que o aumento (quantidade absoluta) na contratação do crédito na maioria das SDRs apenas omite a realidade do crédito catarinense perante a descentralização administrativa. Contudo a análise da participação das SDRs no total dos recursos liberados no período constata que as SDRs, com grande participação no período de 1995 a 2002, continuam detendo considerável participação no período de 2003 a 2010. Quando analisamos a participação das mesorregiões e a participação das SDRs conforme sua distribuição em mesorregiões, é plausível alegar que os recursos continuam centralizados nas mesorregiões da Grande Florianópolis, Vale do Itajaí e Norte Catarinense, ou seja, os recur- sos liberados pelo Badesc não acompanham a proposta de descentralização administrativa catarinense.

A descentralização na verdade deu continuidade à centralização de crédito nas SDRs que possuem destaque econômico. As decisões centradas no governo estadual encontram-se centralizadas nas instâncias das SDRs, e os recursos públicos continuam centralizados, fugindo da proposta do governo estadual de um desenvolvimento equilibrado em todo o território catarinense. Ou seja, no âmbito do crédito, esse modelo torna-se pífio, desmantelando a proposta liberal de governo de "desenvolvimento regional".

Apesar de o governo ser acionista majoritário dessa instituição financeira, o orçamento de aplicação e despesas do Badesc não depende do governo do Estado, ou seja, o Badesc possui autonomia na liberação de recursos e não seguiu o viés governamental, pois a contratação depende primeiramente da iniciativa das SDRs. Outro aspecto a se destacar é que o Badesc direciona seus recursos nas duas esferas, pública e privada, assim, como esperado, os recursos para o setor privado continuariam concentrados nas regiões que possuem concentração de grandes indústrias, pois uma das premissas do sistema capitalista é a centralização de capitais para acumulação capitalista. Ou seja, capital atrai capital. As desigualdades regionais no Brasil também acabam contribuindo para essa distribuição desordenada de indústrias, consequentemente de crédito privado e público, pois o capitalismo necessita de infraestrutura financiada pelo setor público, isso porque há uma insuficiência privada de gestar tais investimentos.

A descentralização administrativa, dessa forma, apenas cria um sistema burocrático e hierarquizado para distribuição de encargos e recursos que não contribui para a disseminação dos recursos regionalmente, como também desestrutura o objetivo de combater o inchaço das cidades litorâneas. Isso porque as mesorregiões Serrana e o Oeste Catarinense diminuíram os recursos contratados no Badesc, enquanto o Vale do Itajaí, Norte Catarinense e Grande Florianópolis, mesorregiões próximas ao litoral, aumentaram a contratação. Ou seja, houve a continuidade da litoralização do crédito. 


\section{Referências}

AFONSO, José Roberto R. A questão tributária e o financiamento dos diferentes níveis de governo. In: AFFONSO, Rui de Britto Álvares; SILVA, Pedro Luiz Barros (Org.). A Federação em perspectiva: ensaios selecionados. São Paulo: FUNDAP, 1995. p. 315-328.

AFFONSO, Rui de Britto Álvares. Descentralização e reforma do Estado: a federação brasileira na encruzilhada. Economia e Sociedade, Campinas, n. 14, p. 127-152, jun. 2000.

. A Federação no Brasil: impasses e perspectivas. In: SILVA, Pedro Luiz Barros; AFFONSO, Rui de Britto Álvares (Org.). A Federação em perspectiva: ensaios selecionados. São Paulo: FUNDAP, 1995. p. 57-75.

AGÊNCIA DE FOMENTO DO ESTADO DE SANTA CATARINA S.A. - BADESC. O BADESC, [s.d.]. Disponível em: <http://www.badesc.gov.br/> Acesso em: 28 ago. 2012.

ALMEIDA, Maria Hermínia Tavares. Federalismo e políticas sociais. In: Revista Brasileira de Ciências Sociais, São Paulo, v. 10, n. 28, p. 90-105, 1995. Disponível em: <http://www.anpocs.org>. Acesso em: 03 abr. 2013.

BATISTA, Lahra Neves. A proposta de descentralização do governo de Santa Catarina: um estudo da SDR de Mafra. In: SEMINÁRIO NACIONAL SOCIOLOGIA E POLÍTICA, 2., v. 6, 2010, Curitiba. Anais eletrônicos... Curitiba: UFPR, 2010. Disponível em: <http://www. seminariosociologiapolitica.ufpr.br $>$. Acesso em: 09 abr. 2013.

CARDOSO DE MELLO, João Manuel. O capitalismo tardio. 9. ed. São Paulo: Brasiliense, 1988. 182 p.

GUIMARÃES DE CASTRO, Maria Helena. Descentralização e política social no Brasil: as perspectivas dos anos 90. In: Espaço \& Debates, São Paulo, v. 11, n. 32, p. 80-87, jan. 1991.
DI PIETRO, Maria Sylvia Zanella. Direito administrativo. 19. ed. São Paulo: Atlas, 2006.

GOULARTI FILHO, Alcides. Crédito, planos e planejamento em Santa Catarina. In: Revista de Sociologia Política, Curitiba, v. 11, n. 22, nov. 2012.

KUGELMAS, Eduardo; SOLA, Lourdes. Recentralização/Descentralização: dinâmica do regime federativo no Brasil dos anos 90. Tempo Social: Rev. Sociol. USP, São Paulo, v. 11, n. 2, p. 63-81, out. 1999.

MEDAUAR, Odete. Direito administrativo moderno. 13. ed. São Paulo: Revista dos Tribunais, 2009.

MEIRELLES, Hely Lopes. Direito administrativo brasileiro. 29. ed. São Paulo: Malheiros, 2004. 798 p.

SANTA CATARINA. Lei Complementar n. 243, de 30 de janeiro de 2003. Estabelece nova Estrutura Administrativa do Poder Executivo, 2003. Disponível em: <www. alesc.sc.gov.br>. Acesso em: 06 out. 2012.

. Lei Complementar n. 284, de 28 de fevereiro de 2005. Estabelece modelo de gestão para a Administração Pública Estadual e dispõe sobre a estrutura organizacional do Poder Executivo, 2005. Disponível em: <www. alesc.sc.gov.br>. Acesso em: 06 out. 2012.

. Lei Complementar n. 381, de 07 de maio de 2007. Dispõe sobre o modelo de gestão e a estrutura organizacional da Administração Pública Estadual, 2007. Disponível em: <www.alesc.sc.gov.br>. Acesso em: 06 out. 2012.

. Lei n. 4.950, de 08 de novembro de 1973. Dispõe sobre a constituição do Banco de Desenvolvimento do Estado de Santa Catarina S.A. - BADESC, e dá outras providências. Disponível em: <www.alesc.sc.gov.br>. Acesso em: 24 abr. 2013.

. Lei n. 10.912, de 15 de setembro de 1998. Dispõe sobre a estrutura e organização do Sistema Financeiro do Estado de Santa Catarina e estabelece outras providências. Disponível em: <www.alesc.sc.gov.br>. Acesso em: 24 abr. 2013.

\section{Anexos}

Anexo 1 - Evolução da participação da distribuição dos recursos do Badesc às mesorregiões 1995-2010 (em \%)

\begin{tabular}{cccccccc}
\hline Anos & $\begin{array}{c}\text { Oeste } \\
\text { Catarinense }\end{array}$ & $\begin{array}{c}\text { Norte } \\
\text { Catarinense }\end{array}$ & Serrana & $\begin{array}{c}\text { Vale do } \\
\text { Itajaí }\end{array}$ & $\begin{array}{c}\text { Grande } \\
\text { Florianópolis }\end{array}$ & $\begin{array}{c}\text { Sul } \\
\text { Catarinense }\end{array}$ & Total \\
\hline 1995 & 14,4 & 16,1 & 16,5 & 12,2 & 29,5 & 11,4 & 100,0 \\
1996 & 15,7 & 20,7 & 0,8 & 9,1 & 49,2 & 4,4 & 100,0 \\
1997 & 57,0 & 10,8 & 1,7 & 20,8 & 4,9 & 4,8 & 100,0 \\
1998 & 24,6 & 17,9 & 2,2 & 32,6 & 11,4 & 11,3 & 100,0 \\
1999 & 21,3 & 31,2 & 5,1 & 14,8 & 15,0 & 12,6 & 100,0 \\
2000 & 20,2 & 16,3 & 6,2 & 25,5 & 12,0 & 19,8 & 100,0 \\
2001 & 14,3 & 21,3 & 4,7 & 29,7 & 13,6 & 16,3 & 100,0 \\
2002 & 15,5 & 23,1 & 5,7 & 25,0 & 11,3 & 19,3 & 100,0 \\
2003 & 18,0 & 32,9 & 0,9 & 23,0 & 12,1 & 13,2 & 100,0 \\
2004 & 26,0 & 15,0 & 4,1 & 27,1 & 9,0 & 18,8 & 100,0 \\
2005 & 20,9 & 30,7 & 13,0 & 26,0 & 3,5 & 5,9 & 100,0 \\
2006 & 15,0 & 24,2 & 5,1 & 33,8 & 18,5 & 3,4 & 100,0
\end{tabular}




\begin{tabular}{cccccccc}
\hline Anos & $\begin{array}{c}\text { Oeste } \\
\text { Catarinense }\end{array}$ & $\begin{array}{c}\text { Norte } \\
\text { Catarinense }\end{array}$ & Serrana & $\begin{array}{c}\text { Vale do } \\
\text { Itajaí }\end{array}$ & $\begin{array}{c}\text { Grande } \\
\text { Florianópolis }\end{array}$ & $\begin{array}{c}\text { Sul } \\
\text { Catarinense }\end{array}$ & Total \\
\hline 2007 & 26,5 & 28,3 & 4,1 & 17,8 & 13,2 & 10,0 & 100,0 \\
2008 & 22,4 & 20,9 & 6,6 & 27,7 & 12,7 & 9,8 & 100,0 \\
2009 & 16,6 & 17,8 & 2,0 & 32,2 & 18,7 & 12,7 & 100,0 \\
2010 & 19,8 & 21,4 & 4,9 & 22,5 & 28,8 & 2,6 & 100,0 \\
\hline
\end{tabular}

Fonte: BADESC - Agência de Fomento do Estado de Santa Catarina

Anexo 2 - Evolução da distribuição dos recursos do Badesc às mesorregiões 1995-2010 (em R\$)

\begin{tabular}{rrrrrrrr}
\hline Anos & \multicolumn{1}{c}{$\begin{array}{c}\text { Oeste } \\
\text { Catarinense }\end{array}$} & $\begin{array}{c}\text { Notarinense } \\
\text { Catarinen }\end{array}$ & \multicolumn{1}{c}{ Serrana } & Vale do Itajaí & $\begin{array}{c}\text { Grande } \\
\text { Florianópolis }\end{array}$ & $\begin{array}{c}\text { Sul } \\
\text { Catarinense }\end{array}$ & \multicolumn{1}{c}{ Total } \\
\hline 1.995 & 13.279 .055 & 14.911 .871 & 15.247 .256 & 11.293 .625 & 27.256 .626 & 10.513 .661 & 81.988 .434 \\
1.996 & 9.765 .014 & 12.880 .704 & 511.149 & 5.648 .320 & 30.597 .003 & 2.733 .724 & 59.402 .190 \\
1.997 & 103.732 .459 & 19.714 .402 & 3.139 .164 & 37.852 .293 & 8.998 .461 & 8.685 .118 & 173.436 .779 \\
1.998 & 17.209 .148 & 12.545 .505 & 1.539 .953 & 22.778 .503 & 7.949 .189 & 7.919 .343 & 62.022 .299 \\
1.999 & 9.674 .851 & 14.184 .087 & 2.310 .326 & 6.734 .412 & 6.832 .124 & 5.716 .230 & 39.735 .801 \\
2.000 & 21.422 .347 & 17.263 .531 & 6.560 .173 & 27.086 .725 & 12.738 .128 & 21.061 .651 & 85.070 .903 \\
2.001 & 26.374 .144 & 39.362 .221 & 8.714 .486 & 54.841 .168 & 25.005 .591 & 30.086 .879 & 154.297 .610 \\
2.002 & 39.280 .780 & 58.379 .451 & 14.476 .007 & 63.275 .667 & 28.522 .353 & 48.787 .311 & 203.934 .258 \\
2.003 & 29.968 .912 & 54.709 .812 & 1.485 .000 & 38.276 .235 & 20.054 .835 & 21.886 .353 & 144.494 .794 \\
2.004 & 27.016 .606 & 15.579 .780 & 4.233 .867 & 28.193 .453 & 9.396 .257 & 19.595 .683 & 84.419 .964 \\
2.005 & 9.962 .392 & 14.583 .492 & 6.177 .874 & 12.362 .296 & 1.676 .147 & 2.813 .799 & 44.762 .200 \\
2.006 & 15.103 .199 & 24.421 .274 & 5.175 .258 & 34.051 .118 & 18.630 .341 & 3.379 .899 & 97.381 .190 \\
2.007 & 32.268 .437 & 34.471 .123 & 4.979 .647 & 21.696 .672 & 16.027 .733 & 12.194 .362 & 109.443 .613 \\
2.008 & 25.760 .281 & 24.047 .338 & 7.569 .473 & 31.827 .448 & 14.617 .686 & 11.251 .039 & 103.822 .226 \\
2.009 & 23.006 .711 & 24.620 .568 & 2.750 .000 & 44.513 .324 & 25.793 .702 & 17.540 .802 & 120.684 .306 \\
2.010 & 31.233 .272 & 33.745 .526 & 7.803 .520 & 35.478 .926 & 45.492 .115 & 4.069 .485 & 153.753 .359 \\
\hline Total & 435.057 .608 & 415.420 .685 & 92.673 .153 & 475.910 .188 & 299.588 .292 & 228.235 .339 & 1.718 .649 .925 \\
\hline
\end{tabular}

Fonte: BADESC - Agência de Fomento do Estado de Santa Catarina 